\title{
A Study of Gender Discourse in Zoya Pirzad Novels
}

\author{
Dr. Foroogh Kazemi \\ Department of Linguistics, Central Tehran Branch, Islamic Azad University, Tehran, Iran. \\ Shohreh Dalaee \\ Department of Linguistics, Central Tehran Branch, Islamic Azad University, Tehran, Iran.
}

\begin{abstract}
In this article, two novels by Zoya Pirzad has been investigated considering Fairclough Critical Discourse Analysis. This article is trying to show how ideology and power of male-characters have influenced on female-characters in these novels. This paper shows that male's patriarchal dialogues that are influenced by society, law and ideology put female characters in challenge and pushes aside their dialogues. This paper has investigated the influence of tradition, culture, and ideology on family life and particularly on people's linguistic interactions from gender point of view. It has been found that the dominant discourse is patriarchal and most of novel females are passive. The research method in this article is analytical and analysis unit is sentences and dialogues of Zoya Pirzad's two novels.
\end{abstract}

Keywords: Critical Discourse Analysis, Gender discourse, Power, Ideology, Persuasion, Zoya Pirzad's 2 Novels.

\section{INTRODACTION}

Critical discourse analysis is an interdisciplinary specialty which emerged during 1960s to mid-1970s following extensive changes in disciplines like anthropology, sociology, psychology, semiotics, and so on and deals with systematic studies of structure, function, and processes of speech generation. Norman Fairclough (1989: 20) believes that discourse analysis has grown in linguistics but has not stopped in linguistics and has entered cultural, social, and political studies and taken a critical form. The main questions in the respective article are: what is the status of gender discourse of male and female characters in interaction with each other from critical standpoint in two novels namely The Acrid Taste of Persimmon and One Day Till Easter? And, in which gender is the lingual hegemony and supremacy seen? This article discusses the relationship between power and gender in discourses. At present, gender inequalities and discriminations are still observed around the world and the governing circumstances in the respective areas enable the men have more power than the women leading to challenged discourses among the individuals. There still exist communities which strongly keep following their old notions based on traditional roles for the women and permanently assume woman as an entity lacking superior discourse power. Hence, this article needs to be discussed to further elucidate the respective gender inequalities. Consequently, the present article seeks to find answers to the following questions: under which conditions, men and women express or reveal their speech weaknesses, and, in which gender is the lingual power and superiority in main characters of the story more noticeable? The data are the texts of the two aforementioned novels analyzed from the perspective of Fairclough's approach. The respective data have been collected via library study and the research is carried out based on analytical method. Also, the analysis unit is the sentences and dialogues of the subjects in Zoya Pirzad's novel, and, the characters of two aforementioned novels are investigated in analyses of lingual means and speech strategies.

\section{REVIEW Of RELEVANT STUDIES}

The studies by Brown \& Levinson (1978: 56) demonstrated that egocentrism in speech is directly related to social position and job class and is not significantly dependent on the individual traits. In their article, Kolb \& Putnam (1997) analyzed egocentrism and attention to men and women's speech in the USA. The assumption in the USA is that women have smaller share in dialogue than men and this assertion was proved in their article.

In the studies by Cansler \& Silies (1981: 441-459), it was demonstrated that in unequal conversations, the egocentric person is the one who more frequently uses the speech components i.e. advice, approval, reflection, and interpretation according to Stilies classification. According to Brown \& Gilman (1972:112) power is an asymmetric relation between at least two persons because it is not possible to assume that, at the same time and from behavioral viewpoint, both parties have equal power such that both of them are able to control the other party's behavior.

Kazemi \& Salmani Siah Balash (2015) studied function of analysis levels in a critical approach to discourse analysis from Fairclough's viewpoint in the movie 'A Separation", and, through review of power relations, culture, and cultural beliefs, they emphasized on the role and position of mythical texts such as holy book in discoursal solution. In another article, Kazemi \& Alizad Monir (2016) critically analyze the discourse in the movie "Gold and Copper" and indicate that how ideology in formation of people's attitudes is manifested in their lingual and social interactions. In their book entitled "Semantic Disputes in Discourses with an overview of the Film Unwanted Wife", Kazemi and Rowshanaifard (2016) showed that the subjects attempt to weaken and challenge the opposing discourses via the strategies like bike-shedding, exaggeration, zeal-provocation, and persuasion.

\section{DISCOURSE ANALYSIS}

The concept of discourse entails all types of political and social acts. Discourse theory is inspired by transformational sciences such as hermeneutics, phenomenology, constructivism, and decomposition. Discourse analysis is used in different senses. It is occasionally used in contrast to context, and, the context here refers to the whole action of establishing relationship including generation and comprehension of information and is not necessarily oral. Therefore, 
discourse analysis comprises subjects like texture, previous information or the common information between the speaker and listener (Bloor \& Bloor, 2007).

\section{Critical Discourse Analysis}

Critical discourse analysis is an evolutionary trend of discourse analysis in linguistic studies which goes beyond the mere description of linguistic data and also takes into account and focuses on ideological processes and situational and intertextual textures in formation of discourse. Norman Fairclough is the critical analyst based on whose views the framework of the present research has been founded.

This approach has different types with varied attitudes. Theorists like Michel Foucault, Kress \& Hach, Penny Cook, Van Dijk, and so on in the west have discussed this matter. The problem of language, ideology, and power are among the fundamental concepts in critical discourse analysis. Scientific study and language description cannot be neutral and unbiased because the social-cultural stance of the analyst compels the context analysis and description to be affected by political factors (Simpson, 1993).

\section{Fairclough Discourse Approach}

Non-critical approaches in linguistics and linguistic phenomena studies do not care about depiction of social formation mechanisms of discourse actions or their social influences and solely focus on descriptive analysis of structure and function of discourse actions whereas critical discourse analysis has paid attention to ideological processes in the discourse, relationships between the language and power, ideology, supremacy, and power of ideologically driven defaults in discourse, inequality in discourse, and so on.

Norman Fairclough has differentiated between the critical objectives and descriptive objectives of discourse. He holds the belief that ideological reflections are regarded as axioms in discourse analysis because of being natural, and ideological reflections have been neglected in analysis of the prevailing discourse during the recent epoch. Discourse analysis using critical method has three levels of analysis: description level in which the context is described and analyzed based on linguistic attributes such as phonetics, phonology, syntax, word formation by means of linguistic morphology and semantics and to some extent, pragmatics, then comes the interpretation level which deals with interpretation of the context based on what expressed in the description level taking into account the texture of situation and concepts and pragmatic strategies of language as well as inter-textual agents. The third one is the depiction level which explains the reason for generation of such contexts by depicting the permissible possibilities available in the respective language for generation in conjunction with sociological and historical parameters besides discourse, ideology, power and contracts, and sociocultural knowledge (Fairclough, 1995).

\section{DATA ANALYSIS}

\section{The First Novel \\ Sample 1}

Description of the Discourse: The guests had left and Mahnaz was washing the dishes in the kitchen.

Faramarz said: "your catering was wonderful; just the fava beans were a little hard, and I guess, you had added too much garlic to the chicken; l'm just saying for your next time. By the way, as I mentioned the next time, please do not talk about our company's affairs in front of the boss. He doesn't like when the woman interfere in the working issues."

Mahnaz kept gazing at the running faucet with one of her hands holding the dish-washing sponge and a glass full of foams in her other hand

Analysis of the Discourse: This discourse implies to traditional culture of Iranian society in which the woman must act as the family's servant and obey her husband. On contrary, the man shall be an independent entity with freedom of action. The common law is also compatible with the men's thoughts and wills, and, they must be mandatorily accepted by all members of the society and shall exist as an unwritten law or ideology. Use of polite imperative verbs and negative imperatives such as "do not talk" has resulted in Faramarz' discourse power. Hence, hegemony is obvious in this discourse. Mahnaz' silence and gazing at the faucet are indicative of her discourse weakness in comparison with his husband's powerful discourse.

\section{Sample 2}

Description of Discourse: Mahnaz had told no one that she had decided to break up with Faramarz. Ten to fifty days earlier, Faramarz was listening to Mahnaz' words sitting exactly on the same chair where Mahnaz' legs were crossed then. Mahnaz said:" just promise me not to tell anyone before it is completely done". Faramarz replied: "I totally agree. However, I know you are again making a mistake this time like all of your other works; but actually, I am tired of constantly teaching you. I thought I could change you. I should have married a woman who would concentrate on her family and house instead of pretending like foreign women and permanently thinking about the company and progress at work and such bullshits." He then touched the bathing towel on the rear kitchen chair and continued: "Obviously, the woman who keeps thinking only about the things outside the house, her bathroom towel must be in the kitchen and her kitchen appliances in the bathroom" Mahnaz said to herself "My God; help me to keep calm; help me not to think about anything else".

Analysis of the Discourse: Secret-keeping and confidentiality of house and family affairs is one of the ideas the women learn at home to avoid being labeled and accused ("just promise me not to tell anyone before it is completely done"). Faramarz' discourse is dominant, superior and governing and endorsed by a great source of power. Therefore, the assured subject of this discourse feels strong and humiliates and marginalizes Mahnaz. This feeling of power and 


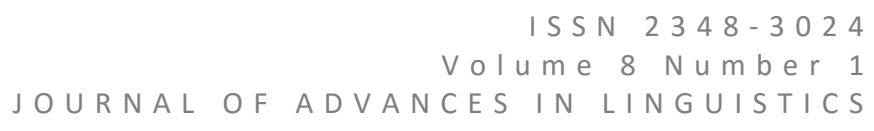

supremacy is absolutely clear in his sentences ("I thought I could change you". "I should have married a woman who would concentrate on her family and house instead of pretending like foreign women". "It's obvious that when a woman keeps thinking only about the things outside the house ..."Faramarz tries to assert himself as superior to his wife in terms of intelligence and comprehension. He is despotic and narcissistic and uses imperative and authoritative words and verbs, such as ("... could change you", "Obviously, the woman who ..." resulting in his hegemonic discourse which properly represents his power and dominance. Here, Faramarz appears as hegemonic signifier causing him to exhibit his supremacist sentiments in interaction with his wife. Based on Fairclough's approach, his power and ideology are seen in this discourse. He also exaggerates Mahnaz' weak points in the same discourse ("obviously, the woman who keeps thinking only about the things outside the house, her bathroom towel must be in the kitchen and her kitchen appliances in the bathroom."Mahnaz just remains silent and talks to herself.

This silence and talk to herself (My God; help me to keep calm; help me not to think about anything else) is an indication of her discourse weakness in response to her husband's discourse.

\section{Sample 3}

Description of the Discourse: Simin and Majid were maternal cousins. One night, Simin's aunt and her husband came over as guests. Simin's aunt said: "Five years will pass at a flash. We can even arrange their marriage right now and send them abroad together". Simin's father said: "It makes no sense for a 16-year old girl to go abroad without his family. Let's even assume she gets married, how old is Majid? An 18-year old boy can barely afford his own life let alone with a wife. No, we won't eat your sweets (as a sign of disagreement with marriage proposal). I don't want my daughter to be engaged. We would talk when Sir. Majid returned"

Analysis and Interpretation of the Discourse: Persuasion strategy has been used in the aunt's discourse (Five years will pass at a flash) in order to persuade the father to accept the marriage. The father's discourse is a gender-based, authoritative, dominant, superior and governing discourse and implies that traditional discourse is still more valid in such a society. This discourse belongs to the culture of the social stratum having an authoritative style of speech. Father's discourse simply manifests and highlights the signs of tradition and ideology with the restrictions he imposes for her daughter and in the form of its words and speech style (It makes no sense for a 16-year old girl to go abroad without his family. Let's even assume she gets married. I don't want my daughter to be engaged). Based on mechanisms of Fairclough's approach, influence of ideology and power is observed in the respective discourse. Father's discourse attempts to persuade the rival discourse (Simin's aunt) by exaggerating and highlighting Majid's weak points (low age and inability to hold the responsibility of marriage in a foreign country). This discourse is reflective of his absolute power in the family as well as his humiliating tone and authoritarian character. The verbs he uses (it makes no sense, and, can barely afford) all disclose the father's masculine and speech power, which has marginalized the discourses of the female addressees.

\section{The Second Novel \\ Sample 4}

Description of the Discourse: My father was a fat and short guy who never liked to admit that he was fat and short. He sat on the chair and put his feet on my writing table and strongly kicked on the table several times. My mom hated this act. Daddy told: "it's entirely your fault! How many times did I tell you he should not propose on this girl?" Mommy reacted: "God may help us. He's gotten crazy again." Not still forgotten mommy's taunt about his appearance, daddy said: "Learn from Shaakeh. Instead of one, she's raising four children. His children are always neat and tidy the same as his house and life. Arsham is two years younger than Edmond. He goes hunting with his father. Your darling boy will escape if he sees a rabbit'.

Nobody could be displeased more. My mother had not become pregnant after my birth.

Analysis and Depiction of the Discourse: Father's discourse under critical conditions is further influenced by his own ideology resulting in dominance of his discourse. The father tries to project his inferiority complex by humiliating his son and as such find faults with the mother's child upbringing style, and also, challenges the mother's maternal and spousal role by comparing his wife with other women so as to get the discourse dominance in this way. Father's discourse is representative of his ideology in which the woman giving birth to many children and perpetually ready for providing services to the family and house is admirable. But, his son lacks this masculine feature and he blames the mother for this weakness and questions her upbringing style. According to Fairclough's approach, impact of ideology and power is noticeable in this discourse. Mother's silence indicates her discourse weakness in face of the father's discourse which is suggestive of his ideology.

\section{CONCLUSION}

Following critical discourse analysis based on Fairclough's approach, the conclusion was reached that the ensemble under analysis undoubtedly has feministic attitudes and the picture presented from woman is a non-independent personality who is dependent on man. At description level, the most frequent words are those pertaining to the family, which are extremely masculine from a feministic standpoint. At analysis and depiction level, the gender-based view, masculine dominant discourse and the power governing the women are clearly observed. In both stories, the masculine entity of the power governing the life of women in the society has been demonstrated using specific words and sentences, and the relatively weak role and position of women in the society has been illustrated based on the discourses. The women in both stories are passive and live with identities dependent on the man. They are merely summarized to their maternal and spousal roles such that they have forgotten their feminine role, feminine identity, and living for themselves. 
The author intends to unveil these masculine signs. In the respective novels, women are seen in the weak and inferior pole and the dominant discourse presumes the woman merely belonging to the house and family environment.

\section{REFERENCES}

1. Bloor, M. and Bloor, T. (2007). The Practice of Critical Discourse Analysis An Introduction, Oxford University Press Inc.

2. Brown, P. and Levinson, S. C. (1987). Politeness: Some Universal in Language.

3. Brown, R. Gilman A. (1972). The Pronoun of Power and Solidarity. Laver and Hutcheson.

4. Cansler, D. C. and Stiles, W. B. (1981). "Relative Statue and interpersonal Presumptuousness." Journal of Experiment of Social Psychology 17, pp. 459 Ed 441.

5. Fairclough, N. (1995) Media Discourse. Critical Discourse Analysis. Boston: Addison Westly.

6. Fairclough, N. (1989). Language and Power, Longman (Second revised edition 2007).

7. Kazemi, F. and Alizadeh Monir, M. (2016); "Critical Discourse Analysis in the Script of the Film "Gold and Copper" based on Laclau \& Mouffe's Approach"; Papers of the $3^{\text {rd }}$ International Conference of Applied Articles in Language Teaching"; University of Tehran.

8. Kazemi, F. and Rowshanaiefard, A. (2016); "Semantic Disputes in Discourses, with an Overview of the Film Unwanted Wife"; Tehran; Arvan Press.

9. Kazemi, F. and Salmani Siah Balash, A. (2015) "Review of Function of Analysis Levels in Critical Approach to Discourse Analysis - Case Study: The Film "A Separation"; Scientific Journal of Linguistic Researches of Tarbiat Modarres University.

10. Kolb, D. M. and Putnam, L. L. (1997). Through the Looking Glass: Negotiation Theory Refracted Through the Lens of Gender. In S. E. Gleason (Ed.), Work Place Dispute Resolution: Directions for the $21^{\text {st }}$ Century (PP. 231 - 257). East Lansing, MI: Michigon State University Press.

11. Simpson, P. (1993). Language, ldeology and Point of View. London: Routledge.

\section{Biography of 1st Author:}

Foroogh Kazemi is head of linguistics department in Central Tehran Branch, Islamic Azad University in Iran. She has published 35 articles and 12 books in linguistics. Dr. Kazemi has been advisor, reader and referee of many linguistic theses and judge of articles in journal of linguistics. Her areas of interest are functional linguistics, sociolinguistics, typology and discourse analysis.

\section{Biography of 2nd Author:}

Shohreh Dalaee is MA student of linguistics, at Central Tehran Branch, Islamic Azad University.

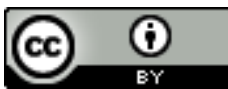

This work is licensed under a Creative Commons Attribution 4.0 International License. DOI : 10.24297/jal.v8i1.6025 